\title{
La Gente/The People
}

\author{
Jonathan Christensen Caballero
}

\begin{abstract}
About the Author
Jonathan Christensen Caballero is a multimedia artist born and raised in Utah. He graduated from Indiana University with an MFA, with an emphasis in ceramics, in Spring 2020. He has exhibited nationally and internationally in venues such as the Clay Center of New Orleans in Louisiana, Standard Ceramic Supply in Pennsylvania, Carbondale Clay Center in Colorado, and Tsukuba Museum of Art in Japan. His work focuses on the human figure and advocates for the Latin American labor community.
\end{abstract}




\section{La Gente/The People}

The personal is political, and I feel a moral imperative to create art that critiques the oppression of Latin American laborers in the United States. My art is based on my personal identity; my mother is a Central American immigrant, and I grew up with parents who supported our family through manual labor jobs. The figures in my work represent people who contribute to society at a cost to their physical bodies. The work is thus rooted in Latin American identity and socioeconomic status.

These sculptures narrate enduring questions of identity through the human figure, pre-Columbian iconography, and the use of mixed media. The figurative work I make is driven by questions of inclusion and exclusion: Who benefits from the American dream? Who in the United States is accorded representation, visibility, and a sense of belonging? Why is the Latin American community forced to remain invisible and to always be perceived as the outsider? My work critiques the oppression of Latin American laborers in this country and advocates for my community's representation by revealing both the plight of the proletariat as well as the resilience of immigrants.

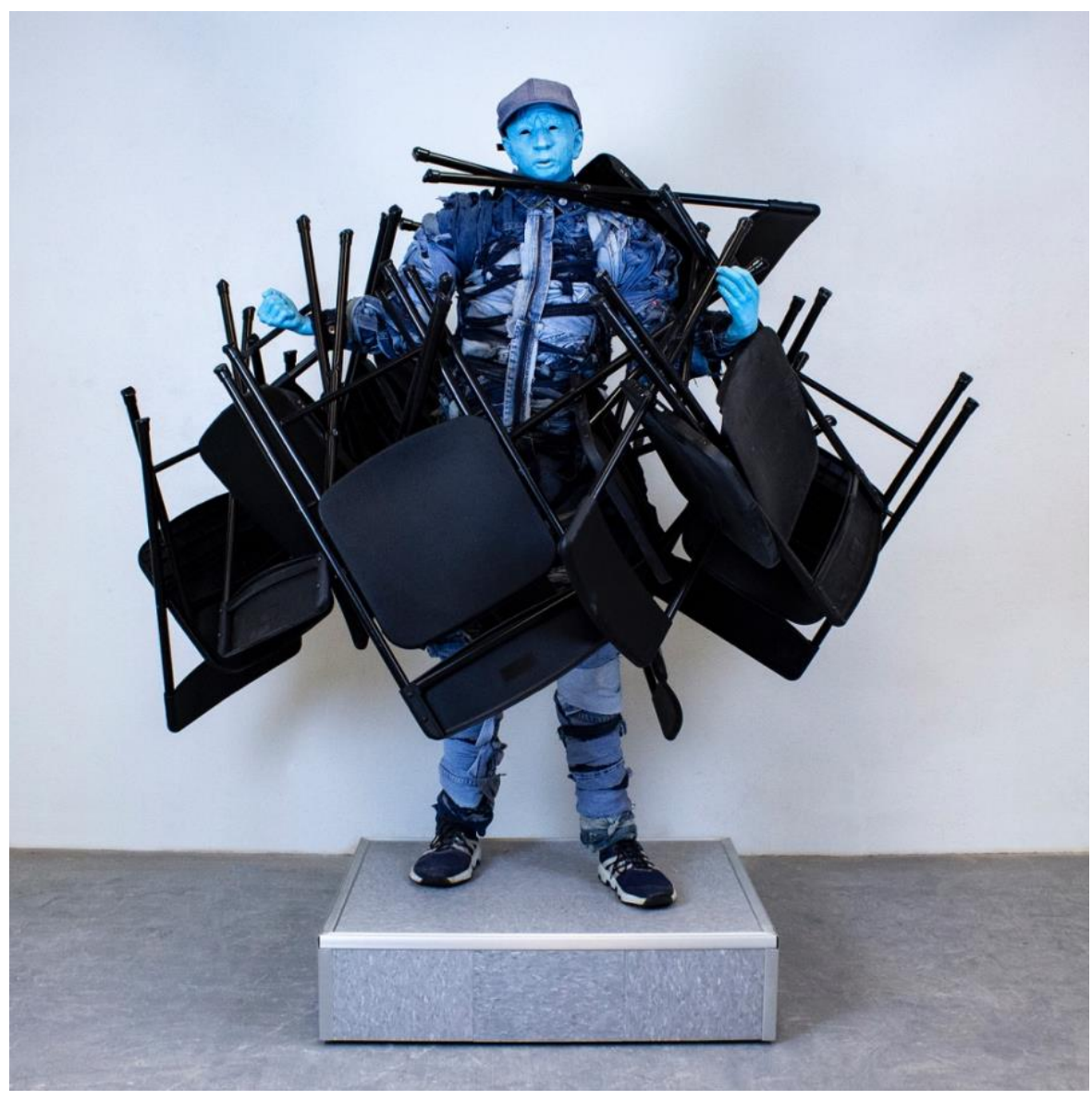

Figure 1

Jonathan Christensen Caballero, Service: Chairs, 2019. Earthenware, secondhand fiber, readymade objects, metal, wood. 


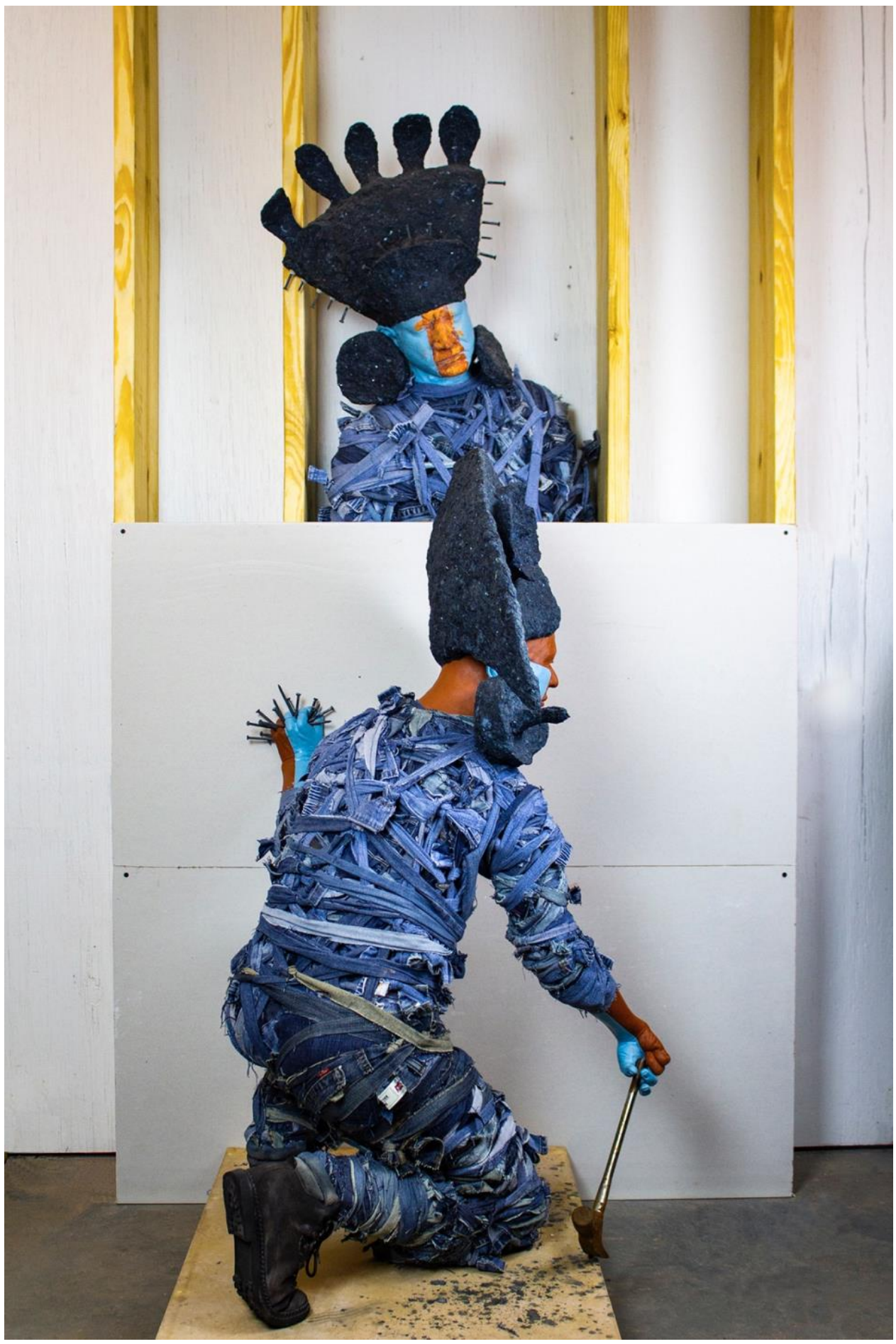

Figure 2

Jonathan Christensen Caballero, Entierro/Burial, 2020. Earthenware, secondhand fiber, drywall, metal, wood. 

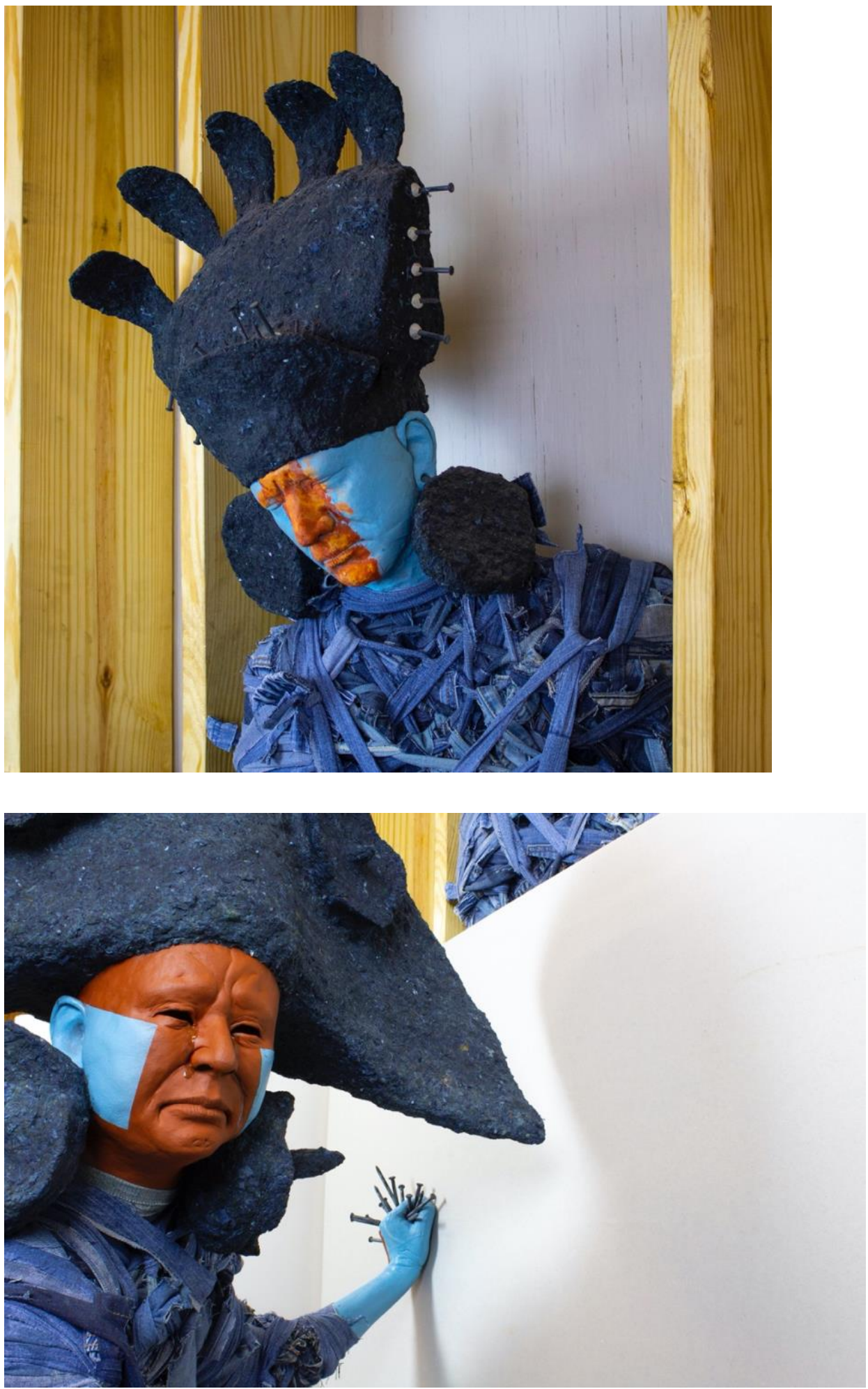

Figure 3, Figure 4

Jonathan Christensen Caballero, Entierro/Burial (detail), 2020. Earthenware, secondhand fiber, drywall, metal, wood. 


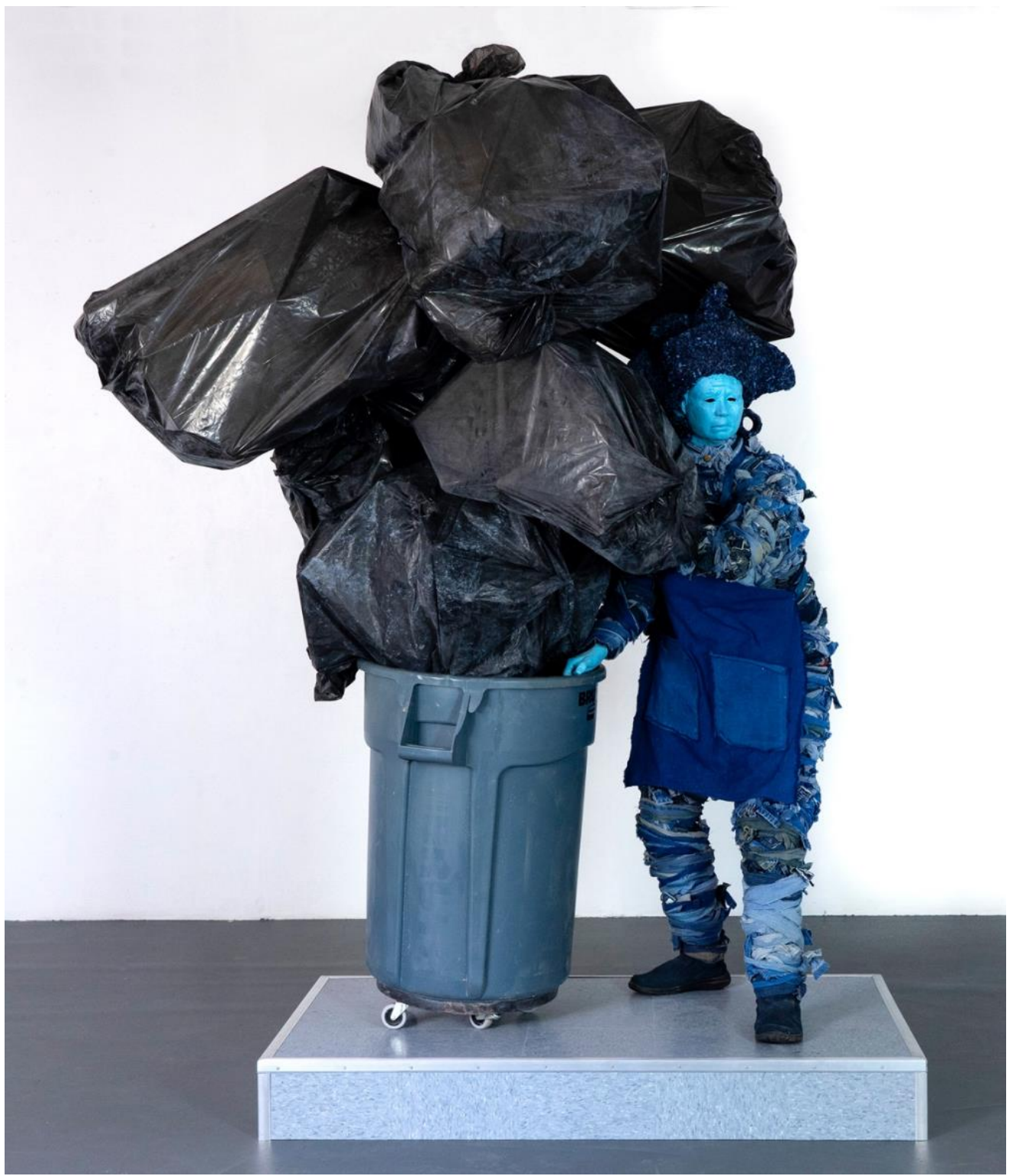

Figure 5

Jonathan Christensen Caballero, Service: Trash, 2019. Earthenware, secondhand fiber, readymade objects, metal, wood. 


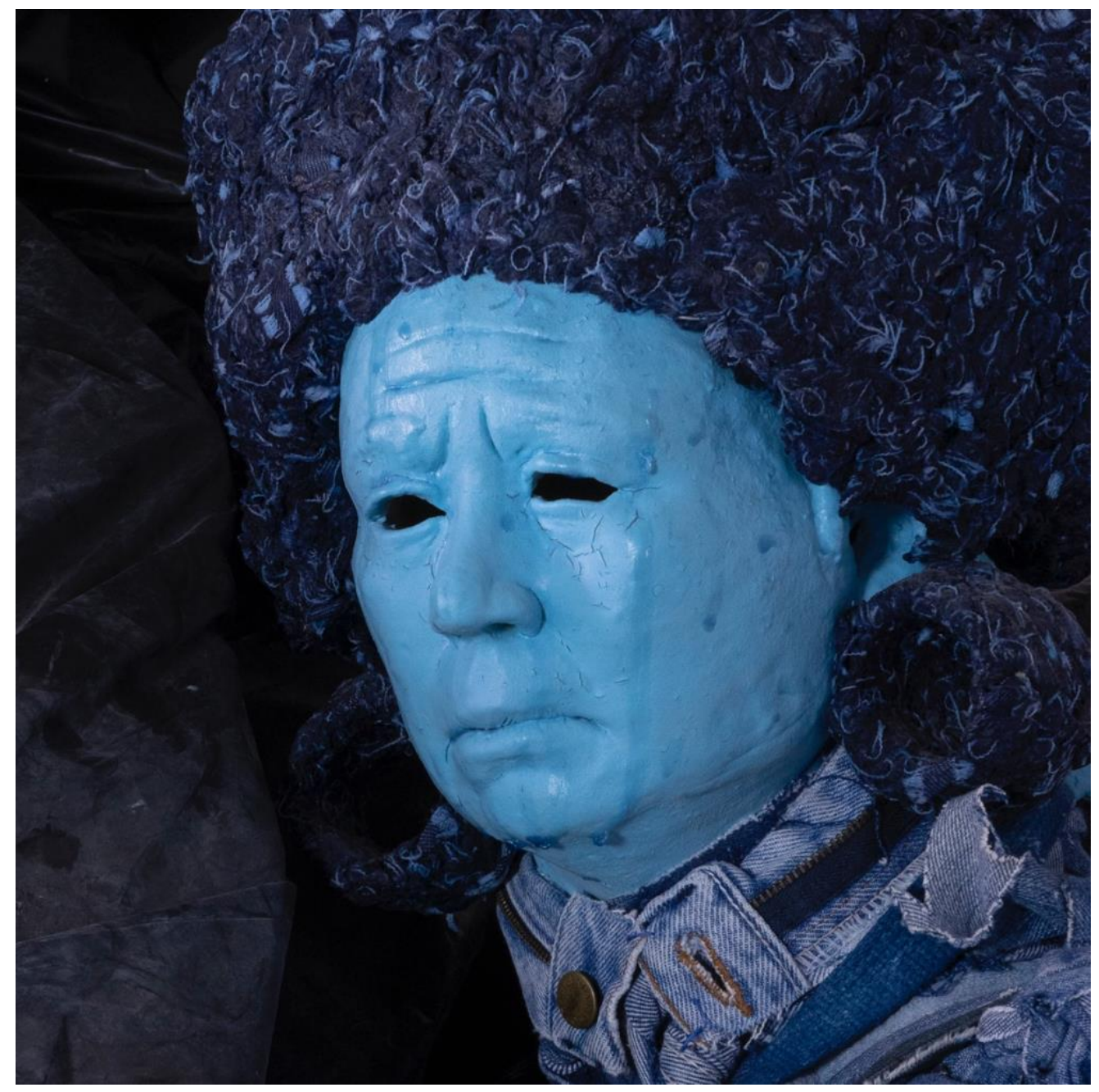

Figure 6

Jonathan Christensen Caballero, Service: Trash (detail), 2019. Earthenware, secondhand fiber, ready-made objects, metal, wood. 


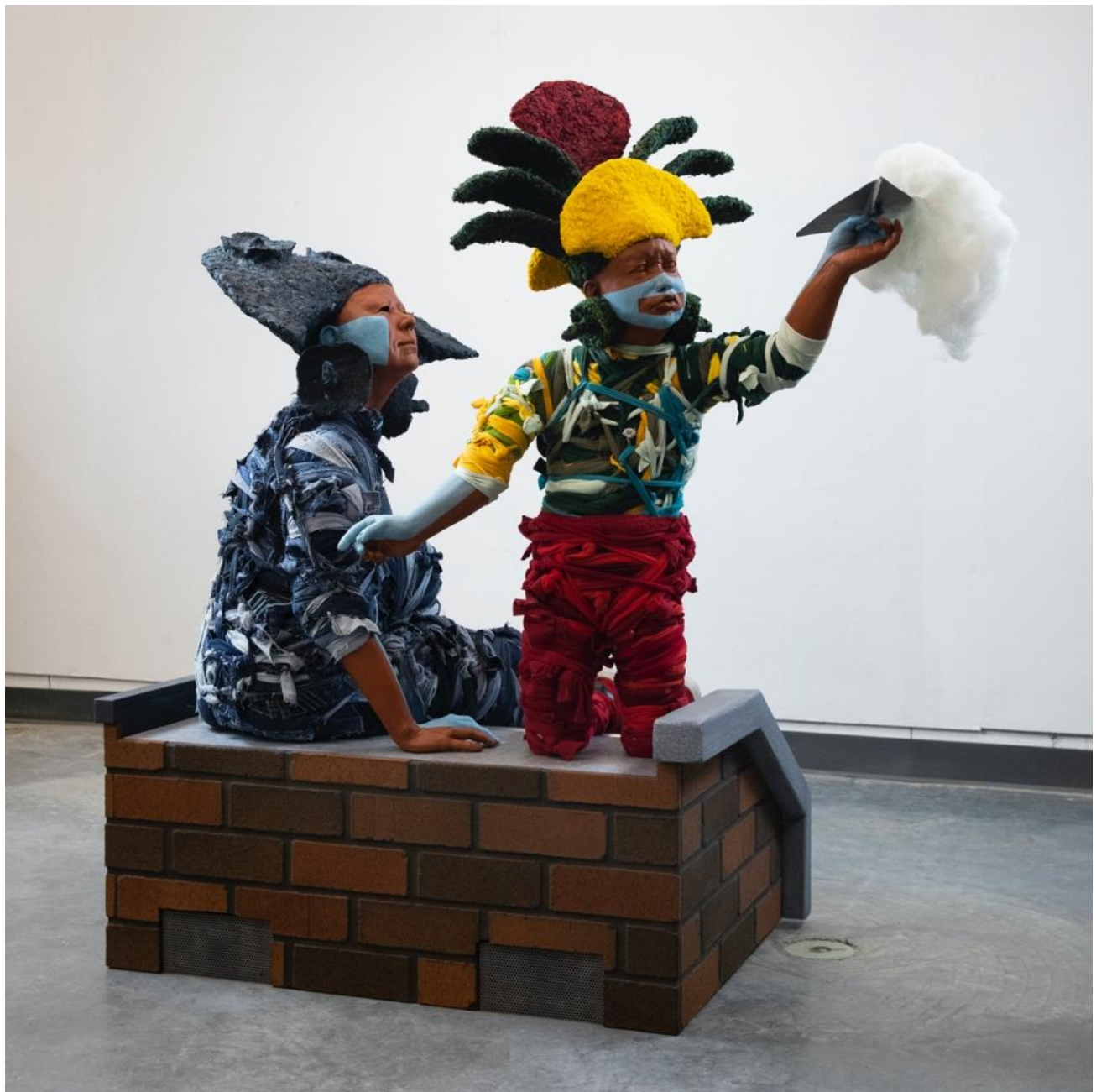

Figure 7

Jonathan Christensen Caballero, Hijo Mio/My Son, 2019. Earthenware, secondhand fiber, readymade objects, metal, wood. 

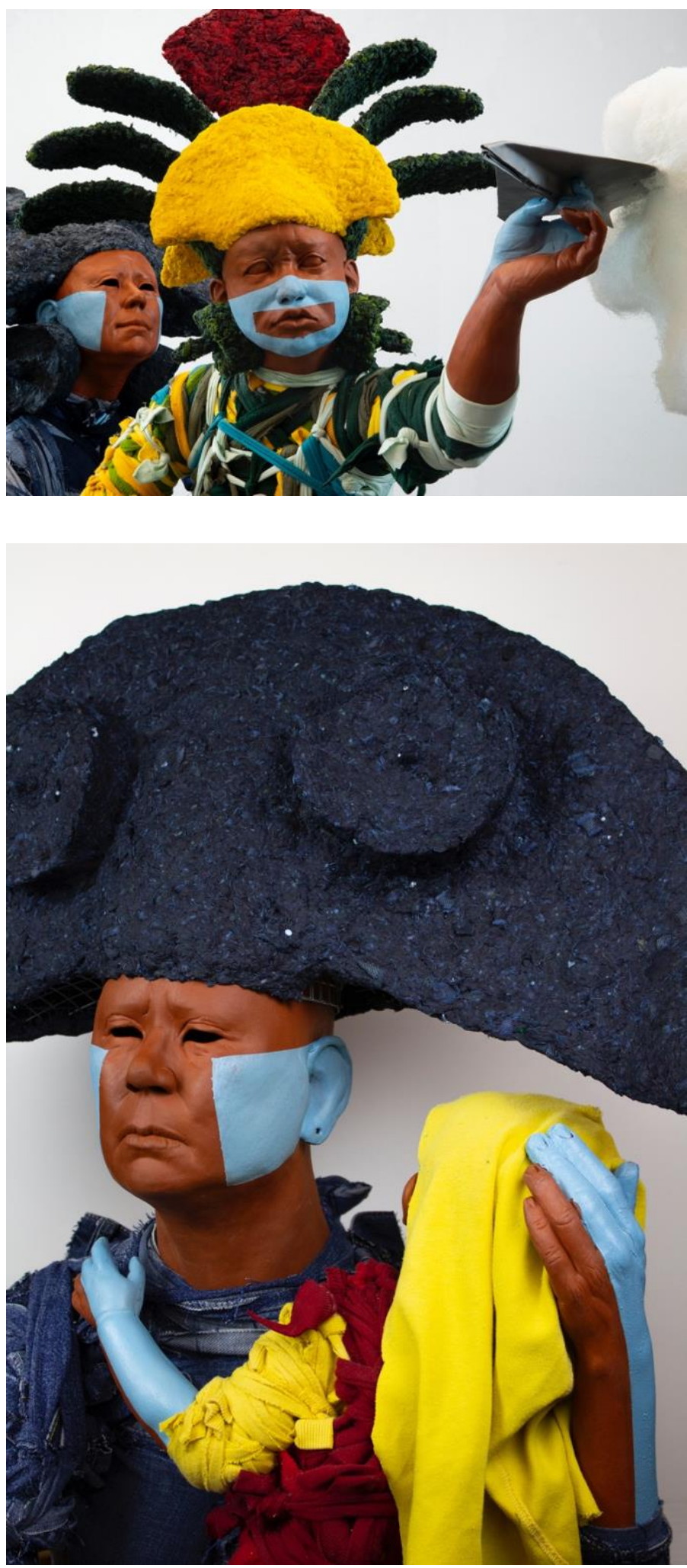

Figure 8, Figure 9

Jonathan Christensen Caballero, Hijo Mio/My Son (detail), 2019. Earthenware, secondhand fiber, ready-made objects, metal, wood. 
Jonathan Christensen Caballero

(cc) $\mathbf{E Y}$

New articles in this journal are licensed under a Creative Commons Attribution 4.0 United States License.

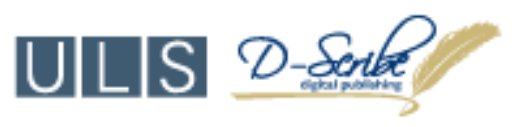

This journal is operated by the University Library System of the University of Pittsburgh as part of its D-Scribe Digital Publishing Program, and is co-sponsored by the University of Pittsburgh Press. 